\title{
Recurso de casación en la forma y el fondo "Seguel con Fisco de Chile"
}

Sentencia pronunciada por la Excma. Corte Suprema, de 30 de julio de 2009 (Rol No 371-2008)

\section{Doctrina:}

- La noción de falta de servicio debe ser analizada independientemente y no en relación a los posibles usuarios del servicio público, pudiendo comprometerse la responsabilidad del Estado por falta de servicio que cause daño a terceras personas que no sean usuarias del órgano estatal que la cometió (Considerando 12\%).

- Cabe aceptar a partir del artículo 2314 del Código Civil, la aplicación a las FFAA de la noción de falta de servicio (Considerando 15\%), por cuanto permite así uniformar el sistema de responsabilidad extracontractual para todos los entes de la Administración del Estado (Considerando 16º).

\section{Normas invocadas:}

Constitución: arts. 19 No 1 y 38 .

Ley Orgánica Constitucional de Bases Generales de la Administración del Estado: arts. $18,21,25$ y 42 .

Ley Orgánica Constitucional de las Fuerzas Armadas: art. $1^{\circ}$

Código Civil: arts. 19, 2314, 2320, 2321, 2322 y 2329 № 1.

Santiago, treinta de julio de dos mil nueve. 


\section{Vistos:}

En estos autos rol No 371-2008 caratulados "Seguel Cares, Pablo Andrés con Fisco de Chile" por indemnización de perjuicios, la parte demandada ha deducido recurso de casación en la forma y en el fondo contra la sentencia de la Corte de Apelaciones de Concepción que confirmó la de primera instancia que acogió la demanda, con declaración que eleva el monto por indemnización por daño moral ordenada pagar a favor del actor a la suma de $\$ 35.000 .000$, sin costas del recurso.

Se trajeron los autos en relación.

\section{Considerando:}

\section{I.- En cuanto al recurso de casación en la forma:}

Primero: Que el Fisco de Chile sostiene que la sentencia impugnada ha incurrido en la causal de nulidad formal del numeral séptimo del artículo 768 del Código de Procedimiento Civil, esto es contener decisiones contradictorias, ello en cuanto el fallo luego de eliminar determinados fundamentos de la sentencia de primera instancia, vuelve a cometer los mismos errores que se denunciaron en la apelación, y así después de razonar en el sentido que la responsabilidad del Estado en estos hechos no es objetiva, concluye en el fundamento séptimo que se debe condenar al Fisco al concurrir las exigencias de daño y causalidad, sin exigir el elemento subjetivo de la culpa del servicio dispensando de ello a la contraparte, lo que es una contradicción;

Segundo: Que al explicar el perjuicio que la causal invocada irroga a su parte, sostiene que si se hubiese mantenido el debate en los términos planteados por las partes, no podría haberse acogido la demanda, por cuanto ésta se fundamentó en forma conjunta e incompatible en diversos regímenes de responsabilidad, tanto objetiva como subjetiva, y el fallo luego de desechar la responsabilidad objetiva termina por condenar a su parte sin exigir el elemento de culpabilidad;

Tercero: Que al analizar la causal de nulidad formal invocada, el recurrente sitúa la contradicción en la circunstancia de afirmarse que la responsabilidad del Estado no es objetiva para luego condenar al Fisco sin exigir el elemento de culpabilidad. Sin embargo del tenor del escrito del recurso, resulta que los hechos en que se funda, no constituyen el vicio de la causal séptima invocada, por cuanto aquél concurre sólo cuando una sentencia contiene decisiones imposibles de cumplir por contraponerse unas con otras; pero no tiene lugar cuando -como lo estima el recurrente- las decisiones se ubican en la parte considerativa de la sentencia, por cuanto ésta solo contiene una, que consiste en que se acoge la demanda intentada condenando al Fisco a pagar una indemnización por daño moral al actor; 


\section{II.- En cuanto al recurso de casación en el fondo:}

Cuarto: Que el Fisco denuncia la vulneración de los artículos 2314, 2320, 2321, 2322 y 2329 No 1 del Código Civil, como de los artículos 19 No 1 y 38 de la Constitución Política de la República, 21 y 18 de la Ley No 18.575 y $1^{\circ}$ de la Ley Orgánica de las Fuerzas Armadas. Explica que la sentencia impugnada acogió la demanda fundándose en los artículos 2314, 2320 y 2322 del Código Civil, señalando que concurren la existencia del daño y la causalidad por lo que condena a su parte, sin mencionar como concurrente el elemento culpa del servicio, lo que constituye una contradicción que conlleva un error de derecho;

Quinto: Que el demandado también reprocha al fallo recurrido el haber establecido la circunstancia que haya quedado demostrada la existencia de un hecho dañoso en perjuicio de un particular que no estaba jurídicamente obligado a soportar, emanado de un agente del Ejército de Chile, parte integrante de las Fuerzas Armadas, es decir de un órgano de la Administración del Estado, como la relación de causalidad entre ambas situaciones, lo que constituye un equívoco pues el Ejército de Chile no está obligado a prestar servicio alguno a la comunidad, ya que su función primordial es la defensa principalmente externa de la soberanía de la nación. Se cita además los artículos 18, 25 y 42 de la Ley de Bases de la Administración del Estado que excluye de la aplicación de la norma de falta de servicio al Ejército de Chile, por lo que en realidad no existe sino una responsabilidad civil personal respecto del funcionario militar que incumplió sus deberes. Así la sentencia cuando aplica el artículo 38 de la Constitución Política de la República le da un alcance que no tiene lo que ocurre también con el artículo 2314 del Código Civil al extenderlo a la noción de falta de servicio, violentando de esta manera el artículo 19 del Código Civil al dejar de aplicar el tenor literal del artículo 21 de la Ley No 18.575 que hace inaplicable la responsabilidad consagrada en esa ley al Ejército de Chile;

Sexto: Que finalmente se denuncia que la sentencia atacada vulnera los artículos 2314, 2320 y 2322 del Código Civil al dejar de exigir el elemento de responsabilidad civil por el hecho propio cual es el elemento subjetivo atributivo de culpa del servicio;

Séptimo: Que al explicar cómo los errores de derecho denunciados han influido sustancialmente en lo dispositivo del fallo, seńala que de no haberse incurrido en ellos, no podría haberse dejado de exigir y configurar la obligación de concurrencia de la culpa y por ende no podría haberse acogido la demanda por el solo hecho de existir daño y relación de causalidad como lo hizo erradamente el fallo;

Octavo: Que son hechos de la causa por así haberlos establecido los jueces del grado los siguientes:

A.- Que el día 3 de mayo de 2001, el conscripto Pablo Andrés Seguel Cares se encontraba desarrollando ejercicios de instrucción básica, en el marco de la ejecución de su servicio militar, cuando sorpresivamente sufrió un impacto de bala en su brazo derecho, proveniente de un disparo efectuado por el cabo 2º Héctor Hernán Herrera Villa, quien 
no cumplió una orden superior tendiente a no utilizar munición de guerra en dicho ejercicio, sino que sólo de fogueo. Que como consecuencia de dicho impacto, el actor aún tiene alojadas en su pulmón esquirlas de bala que no han podido ser extraídas por el grave riesgo que ello importaría para su salud, presentando además una lesión en su brazo derecho que disminuye su sensibilidad, fuerza y en general la funcionalidad de dicha extremidad (considerando noveno de la sentencia de primera instancia);

B.- Que a raíz del accidente sufrido y las consecuenciales secuelas experimentadas, el actor, antes un joven alegre, trabajador y deportista, ahora está convertido en un sujeto deprimido, amargado por no poder desarrollarse con normalidad en el campo laboral e impedido de realizar actividades de antaño. A ello se suma el hecho de ser éste un joven de 23 ańos en la actualidad, etapa de la vida en que es más doloroso el hecho de acarrear una limitación por el resto de sus días, lo que indudablemente también afecta y afectará su vida en todos sus aspectos (motivo décimo noveno de la sentencia de primer grado);

C.- Que es de toda lógica pensar que el hecho de haber recibido un disparo en la zona de la extremidad derecha, incluyendo perforación en aquel pulmón, de manera tan sorpresiva y más aún, mientras cumplía su servicio militar, ha producido al señor Seguel una aflicción, un dolor, en síntesis, una afectación en sus sentimientos, ya sea producto del hecho mismo de verse pronto, sometido a exámenes, tardar en recuperarse, tener fragmentos de bala alojados en su cuerpo, perder sensibilidad en aquella extremidad, verse incluso afectado en su estética, debido a las cicatrices que se observan en su cuerpo, en las fotografías acompañadas a fojas 43 y tener una incertidumbre sobre su futuro respecto al campo ocupacional (considerando décimo noveno del fallo de primera instancia);

Noveno: Que sobre tales hechos, los jueces del grado estimaron que habiéndose establecido que el Estado causó un daño interviniendo un funcionario de las Fuerzas Armadas, debe responder por falta de servicio por aplicación del artículo 2314 y siguientes del Código Civil. Así la sentencia de segundo grado luego de hacer expresa cita del motivo noveno del fallo de primera instancia que hace mención a que un funcionario del Ejército utilizó munición de guerra en los ejercicios militares y no de fogueo como estaba ordenado hiriendo al demandante, dispone que concurren las exigencias del daño y la causalidad fijando en definitiva una indemnización por daño moral a favor del actor;

Décimo: Que el recurso interpuesto por la defensa fiscal descansa en tres grandes argumentos, cuales son que se prescindió del elemento de culpa para condenar al Estado, que el Ejército de Chile no puede incurrir en falta de servicio porque no está obligado a prestar ningún servicio a la comunidad, que no puede extenderse la aplicación del artículo 2314 del Código Civil a la noción de falta de servicio y que al hacerlo se violenta la ley No 18.575 que expresamente hace excepción de ello en relación a las Fuerzas Armadas; 
Undécimo: Que corresponde desechar el primero de los reproches invocados tanto en el recurso de casación en la forma como en el de fondo basado en la prescindencia del elemento subjetivo de culpabilidad necesario para condenar. En efecto, tal como se asentó precedentemente en el motivo noveno de esta sentencia el fallo de alzada hace expresa mención al considerando noveno de primera instancia en cuya parte el sentenciador dejó claramente sentado que en un ejercicio de instrucción básica, en el marco de la ejecución del servicio militar realizado por el demandante, éste recibe un disparo efectuado por un cabo $2^{\circ}$ del Ejército que no cumplió una orden superior tendiente a no utilizar munición de guerra en dicho ejercicio sino solo de fogueo. Tal razonamiento no es sino el reflejo de una negligencia de parte de la Institución en cuanto a que en un ejercicio donde sólo se debe utilizar un armamento inofensivo, se utilizó uno de guerra que permitió en definitiva la existencia del daño. Por ello se explica que después de efectuada la referencia al fallo de primer grado, los magistrados de segunda instancia completen el razonamiento señalando que concurren el daño y la causalidad, lo que permite en definitiva condenar al Fisco de Chile, por lo que el error denunciado no es tal y debe ser descartado;

Duodécimo: Que en cuanto al argumento que no es posible que el Ejército de Chile incurra en falta de servicio, al no prestar servicio alguno a la comunidad, ello también es errado. En efecto, la Falta de Servicio se presenta como una deficiencia o mal funcionamiento del servicio en relación a la conducta normal que se espera de él y así doctrinaria y jurisprudencialmente se ha estimado que concurre cuando el servicio no funciona, debiendo hacerlo, cuando funciona irregularmente o tardíamente. En el caso que nos ocupa, el Estado se escuda en el hecho que el Ejército de Chile tiene como función primordial la defensa de la soberanía de la nación, sin embargo no debe olvidarse que para cumplir esa misión recluta jóvenes que cumpliendo con su obligación legal del servicio militar, permanecen en el Ejército durante un tiempo en que son entrenados de diversas formas para cumplir el objetivo primordial cual es la defensa de la soberanía, oportunidad en que lo que se espera de la Institución es el debido entrenamiento de los reclutas dentro de un marco de seguridad que garantice su integridad, situación que en autos no ha acontecido en la medida que un funcionario del Ejército utiliza armamento de guerra en los ejercicios básicos y no de fogueo que es lo esperable, de tal suerte que precisamente la falta de servicio consiste en haber entregado una munición de guerra y no de fogueo a un funcionario que participaría en entrenamientos militares, quien utilizándolos en el ejercicio de sus funciones indebidamente hirió en definitiva al actor. Por otra parte la noción de falta de servicio debe ser analizada independientemente y no en relación a los posibles usuarios del servicio público, pudiendo comprometerse la responsabilidad del Estado por falta de servicio que cause daño a terceras personas que no sean usuarias del órgano estatal que la cometió.

Décimo tercero: Que el tercer fundamento del recurrente de casación, radica en la extensión indebida del artículo 2314 del Código Civil hacia la noción de falta de servicio. Al respecto cabe primeramente reflexionar que constituye un error el plantear 
por una parte que se ha aplicado el artículo 2314 del Código Civil prescindiendo del elemento de culpabilidad -lo que supone aceptar su aplicación- para luego argüir que no corresponde aplicarlo al caso de autos, lo que supone entonces la existencia de errores alternativos que no son propios de un recurso de derecho estricto. Sin embargo aún cuando esto bastase para desechar el recurso, esta Corte considera necesario analizar el tema debatido dada su importancia;

Décimo cuarto: Que en efecto, hasta antes de la dictación de la Ley No 18.575 la responsabilidad del Estado se determinaba a través de la aplicación del artículo 2320 del Código Civil, sin embargo la situación varía con la promulgación de la Ley de Bases de la Administración del Estado el 5 de diciembre de 1986 que incorporó al Derecho Público chileno el sistema de responsabilidad extracontractual del Estado elaborado por el derecho administrativo francés, principalmente a través de la jurisprudencia del Consejo de Estado, que en opinión de la mayoría de los autores, constituye la mejor solución lograda por el derecho, para asegurar un debido equilibrio entre los derechos de los particulares y los intereses públicos. La ley contempló entonces el artículo 44 -hoy 42- que prescribió que "Los órganos de la Administración serán responsables del daño que causen por falta de servicio. No obstante, el Estado tendrá derecho a repetir en contra del funcionario que hubiere incurrido en falta personal" Sin embargo se excluyó de la aplicación del título II sobre normas especiales, donde había quedado ubicado el artículo 44, a la Contraloría General de la República, al Banco Central, a las Fuerza Armadas y de Orden y Seguridad, a las Municipalidades, al Consejo Nacional de Televisión y a las empresas públicas creadas por ley. Todo ello en el inciso segundo de su artículo 18 -actual 21-;

Décimo quinto: Que entonces cabe dilucidar qué sistema resulta aplicable a las instituciones excluidas, y en el caso particular a las Fuerzas Armadas; para ello ha de recurrirse al derecho común, teniendo presente que precisamente el desarrollo del derecho administrativo, allí donde ha ocurrido, ha sido a partir de la distinta interpretación de las normas de derecho común para el Estado y para las relaciones entre particulares, permitiendo de esta forma la conciliación de la actuación estatal, dotada de imperio público, como guardiana del interés colectivo, con la protección de los derechos de los ciudadanos, de tal suerte que cabe aceptar la aplicación en nuestro país a partir del artículo 2314 del Código Civil, de la noción de falta de servicio. En efecto al Estado como a los otros entes públicos administrativos, pueden serle aplicados de manera diversa las normas del Título XXXV del Código Civil, sin que esto implique desde luego, una errada interpretación de las mismas. Es así que las personas jurídicas son capaces de culpa, aunque carezcan de voluntad propia. La culpa civil como seńalan los hermanos Mazeaud y André Tunc, "no requiere la voluntad, ni siquiera el discernimiento, no es necesariamente una culpa moral; es suficiente con comportarse de manera distinta a la que habría observado en parecidas circunstancias un individuo cuidadoso". De acuerdo con este razonamiento y ampliándolo, puede no exigirse para la responsabilidad de la persona jurídica Estado la culpa o dolo de sus órganos o representantes; basta con que el comportamiento del servicio público fuera distinto 
al que debiera considerarse su comportamiento normal; o sea basta con probar una falta de servicio. Por otra parte la culpa de funcionarios anónimos puede presumirse, como ha hecho en ocasiones la jurisprudencia, en estos casos la culpa del órgano, que se presume de los hechos mismos, constituye la culpa del Estado;

Décimo sexto: Que del modo que se ha venido razonando, es acertada la aplicación del artículo 2314 del Código Civil y la institución de la falta de servicio a la litis planteada, por cuanto permite así uniformar el sistema de responsabilidad extracontractual para todos los entes de la Administración del Estado.

Por estas consideraciones y lo dispuesto en los artículos 764, 765, 767, 805 y 806 del Código de Procedimiento Civil, se rechazan los recursos de casación en la forma $y$ en el fondo deducidos en lo principal de fojas 186 contra la sentencia de doce de noviembre de dos mil siete, escrita a fojas 180 .

Regístrese y devuélvase con sus agregados.

Redacción a cargo del Ministro señor Pierry.

Rol No 371-2008

Pronunciado por la Tercera Sala de esta Corte Suprema integrada por los Ministros Sr. Adalis Oyarzún Miranda, Sr. Héctor Carreño Seaman, Sr. Pedro Pierry Arrau, Sra. Sonia Araneda Briones y Sr. Haroldo Brito Cruz. No firma el Ministro Sr. Oyarzún no obstante haber estado en la vista y acuerdo de la causa, por estar ausente al momento de firmar. Santiago, 30 de julio de 2009.

Autoriza la Secretaria de esta Corte Suprema Sra. Rosa María Pinto Egusquiza.

En Santiago, a treinta de julio de dos mil nueve, notifiqué en Secretaría por el Estado Diario la resolución precedente. 